\title{
Incidence and mortality rates of keratinocyte carcinoma from 1998-2017: a population-based study of sex differences in Ontario, Canada
}

\author{
Evan Tang BSc, Kinwah Fung MSc, An-Wen Chan MD DPhil
}

Cite as: CMAJ 2021 October 4;193:E1516-24. doi: 10.1503/cmaj.210595

\begin{abstract}
Background: Keratinocyte carcinoma is the most common malignant disease, but it is not captured in major registries. We aimed to describe differences by sex in the incidence and mortality rates of keratinocyte carcinoma in Ontario, Canada.
\end{abstract}

Methods: We conducted a populationbased retrospective study of adults residing in Ontario between Jan. 1, 1998, and Dec. 31, 2017, using linked health administrative databases. We identified the first diagnosis of keratinocyte carcinoma using a validated algorithm of health insurance claims, and deaths related to keratinocyte carcinoma from death certificates. We calculated the incidence and mortality rates of keratinocyte carcinoma, stratified by sex, age and income quintile. We evaluated trends using the average annual percentage change (AAPC) based on joinpoint regression.

Results: After decreasing from 1998 to 2003, the incidence rate of keratinocyte carcinoma increased by $30 \%$ to 369 per 100000 males and 345 per 100000 females in 2017 (AAPC 1.9\%, 95\% confidence interval [Cl] 1.7 to 2.1 from 2003 to 2017). The incidence rate was higher in females younger than 55 years, but higher in males aged 55 years or older. Between 2008 and 2017, the incidence rate rose faster in females than males aged $45-54$ years (AAPC $1.2 \%$ v. $0.5 \%$, $p=0.01)$ and $55-64$ years (1.2\% v. $0.1 \%$, $p<0.01)$. The incidence was higher in males than females in the higher income quintiles. Between 1998 and 2017, the mortality rate of keratinocyte carcinoma was 1.8 times higher in males than females, on average, and rose 4.8 -fold overall (AAPC 8.9\%, 95\% Cl 6.4 to 11.4 in males; $8.0 \%, 95 \%$ CI 5.3-10.8 in females).

Interpretation: The population burden of keratinocyte carcinoma is growing, and the incidence and mortality rates rose disproportionately among certain sex- and age-specific groups. This warrants further investigation into causal factors and renewed preventive public health measures.
K eratinocyte carcinoma comprises basal and squamous cell carcinomas, and is the most common malignant disease in Canada and the United States. ${ }^{1-5}$ Although keratinocyte carcinoma has a low mortality rate, it is associated with substantial morbidity and impaired quality of life. ${ }^{2,6,7}$ Among cancers, it also ranks fifth in health care costs in the US. ${ }^{8}$

Epidemiological studies of keratinocyte carcinoma in North America are limited by its exclusion from most cancer registries. ${ }^{9}$ Previous studies found that higher overall incidence of keratinocyte carcinoma is associated with male sex, ${ }^{10-14}$ older age ${ }^{15-17}$ and higher socioeconomic status. ${ }^{18-21}$ However, differences in the incidence and mortality rates of keratinocyte carcinoma by sex in relation to age and socioeconomic status have not been well characterized.

A better understanding of the epidemiology of keratinocyte carcinoma in Canada and differences by sex would inform public health initiatives, health services policy and patient education strategies. This is particularly relevant now, given the recent regulatory approval of systemic immunotherapies for locally advanced or metastatic squamous and basal cell carcinoma. ${ }^{22-25}$ Our objective was to identify the population-based incidence and mortality trends of keratinocyte carcinoma in Ontario, Canada over 2 decades and to evaluate sex differences.

\section{Methods}

We conducted a population-based, retrospective observational study of health administrative data sets that were linked using unique encoded identifiers and analyzed at ICES. We reported the study according to the Reporting of Studies Conducted Using Observational Routinely-Collected Health Data (RECORD) checklist. ${ }^{26}$ 


\section{Population}

We included adults ( $\geq 18 \mathrm{yr}$ ) residing in Ontario between Jan. 1, 1998, and Dec. 31, 2017. We excluded those who were ineligible for health coverage under the Ontario Health Insurance Plan (OHIP), which insures essential hospital and physician-delivered medical services for Ontario residents. As we were interested in the first incidence of keratinocyte carcinoma, we excluded anyone who had such a diagnosis before 1998 using a lookback window of at least 6 years until 1992, based on data availability.

\section{Outcomes and variables}

We counted the first recorded incidence of keratinocyte carcinoma per person and ignored tumours subsequently documented in the database. Since keratinocyte carcinoma is not captured by the Ontario Cancer Registry, we used a validated algorithm of OHIP claims (83\%-85\% sensitivity, 93\%-99\% specificity) to ascertain diagnoses of keratinocyte carcinoma (Appendix 1, Supplemental Methods, available at www.cmaj.ca/lookup/ doi/10.1503/cmaj.210595/tab-related-content). ${ }^{27}$ The algorithm uses data from reimbursement claims (i.e., skin procedures and diagnosis codes from the International Classification of Diseases, 9th Revision [ICD-9] within a 180 day period in the OHIP claims database) submitted by fee-for-service physicians and laboratories in the province's health care system and hospital discharge records from the Canadian Institute for Health Information (ICD-9 and ICD-10-CA diagnosis codes in the Discharge Abstract and Same-Day Surgery Databases).

We extracted sociodemographic information, including sex, age, socioeconomic status and date of death, from the Registered Persons Database (RPDB), maintained by the Ontario Ministry of Health and Long-Term Care. The RPDB includes all residents of Ontario eligible for OHIP coverage. We determined socioeconomic status by associating the postal code with the average Census-based income quintile of the neighbourhood, with quintile 1 having the lowest income. For each year, we applied income data from the nearest Census, conducted up to 2 years earlier or later.

We identified deaths from keratinocyte carcinoma through the Ontario Registrar General Database, which contains cause of death information with $95 \%$ sensitivity and $86 \%$ specificity. ${ }^{28}$ We attributed deaths to keratinocyte carcinoma if it was noted as a primary or contributing cause of death on the death certificate based on ICD-9 and ICD-10 diagnosis codes.

All data sets were linked deterministically at ICES using OHIP numbers with greater than $99.9 \%$ completeness, except for the Ontario Registrar General Database, which were linked deterministically and probabilistically using direct identifiers (i.e., name, postal code, date of birth), with $96 \%$ completeness.

\section{Statistical analysis}

We derived annual crude incidence and mortality rates with 95\% confidence intervals ( $\mathrm{Cls}$ ) using the annual number of patients with their first diagnosis of keratinocyte carcinoma (incidence rate) or fatal keratinocyte carcinoma (mortality rate) as the numerator, and the adult population count from the
RPDB as the denominator. We used direct standardization methods and the 1991 Canadian population to calculate ageand sex-standardized rates.

We plotted annual incidence rates over time, stratified by sex, age group (using census categories) and income quintile. We analyzed data using joinpoint regression to identify changes in rate trends over the study period. ${ }^{29}$ We calculated the average annual percent change (AAPC) for each trend segment, as well as the most recent 10 years (2008-2017), as the weighted average of the slope coefficients of the joinpoint regression line over the applicable time interval, with weights equal to each segment length captured within the interval. To identify pairwise differences in AAPC, we used the test of parallelism to compare the joinpoint regression mean functions of males and females. ${ }^{30}$ We conducted analyses using the Joinpoint Regression Program version 4.8 (Statistical Research and Applications Branch, National Cancer Institute).

As most keratinocyte carcinomas occur in white people, we conducted a secondary analysis to estimate the incidence and mortality rates in white adults, accounting for the rising proportion of people representing visible minority groups over the study period. As data on race were not available in the ICES databases, we used data from the Canadian Censuses from 1996 to 2016, with linear interpolation between census years, to obtain the proportion of the Ontario population that was white. We estimated the number of white adults by multiplying the denominators of the incidence and mortality rates by these proportions. We multiplied the numerators by $97 \%$, which was the proportion of patients with keratinocyte carcinoma who were white in population-based data from transplant recipients in Ontario. ${ }^{31}$

\section{Ethics approval}

ICES is an independent, nonprofit research institute whose legal status under Ontario's health information privacy law allows it to collect and analyze health care and demographic data, without consent, for health system evaluation and improvement. The use of the data in this project is authorized under section 45 of Ontario's Personal Health Information Protection Act and does not require review by a Research Ethics Board.

\section{Results}

The incidence of keratinocyte carcinoma in 2017 was 356.7 per 100000 adults; the incidence rate was higher in males (369.3 per 100000 ) than females ( 344.6 per 100000 ). From 1998 to 2017, a total of 646480 adults were diagnosed with a first keratinocyte carcinoma, and the median age at first diagnosis rose from 37.5 to 40.7 years. During this period, the adult population in Ontario grew from 8921563 in 1998 to 11562915 in 2017 (Figure 1), and the ratio of females to males remained consistent between 1.04 and 1.06 annually. ${ }^{32}$

We noted a V-shaped pattern in the crude annual incidence rates over the study period (Table 1, Figure 1). From 1998 to 2003, rates of first diagnosis of keratinocyte carcinoma declined annually, from a crude incidence rate of 328.6 to 274.2 per 


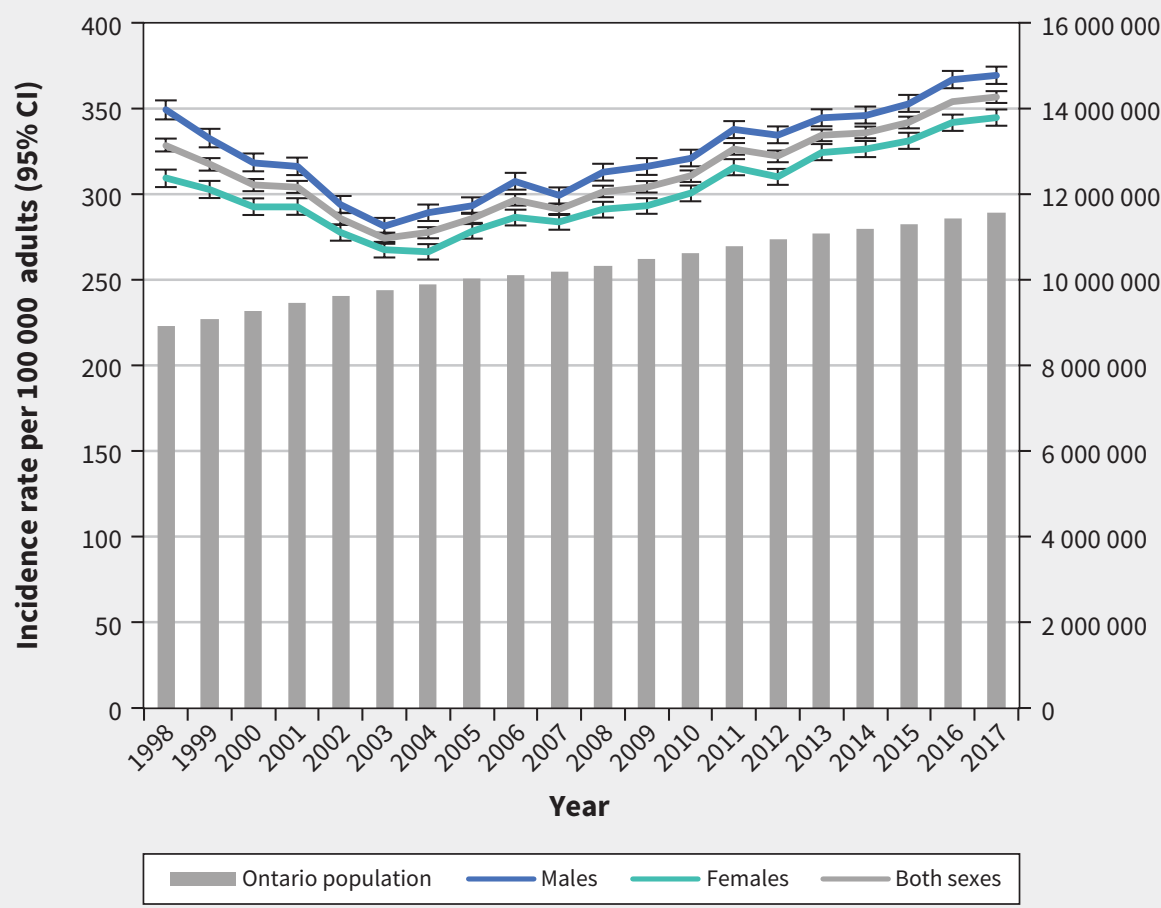

Figure 1: Annual crude incidence rates of first diagnosis of keratinocyte carcinoma (solid lines) and Ontario adult population size (vertical bars) from 1998 to 2017. Note: $\mathrm{Cl}=$ confidence interval.

100000 adults (AAPC $-3.6 \%, 95 \% \mathrm{Cl}-4.4 \%$ to $-2.8 \%$ ). This decline was followed by a steady rise to a rate of 356.7 per 100000 in 2017 (AAPC $1.9 \%, 95 \% \mathrm{Cl} 1.7 \%$ to $2.1 \%$ ), representing an increase of $30 \%$ over the $14-y e a r$ period. Age- and sex-standardized incidence rates followed similar trends, though the rate of increase after 2003 was attenuated (AAPC $0.7 \%, 95 \% \mathrm{Cl} 0.5 \%$ to $0.9 \%$ ) compared with crude rates (Table 1). Given the distinct, opposite incidence trends between the earlier and later segments of the study period, we focused on the incidence data from the most recent 10 years (2008-2017).

Overall, the annual incidence of keratinocyte carcinoma in males was higher than in females in all calendar years, but differences by sex were highly dependent on age. The sex-stratified annual incidence of keratinocyte carcinoma in adults rose with age, ranging from a low of 26.1 per 100000 males aged $18-34$ years to a high of 1156.4 per 100000 males aged $\geq 65$ years in 2017 (Figure 2). Males had a higher incidence of keratinocyte carcinoma than females among adults older than 55 years of age, whereas keratinocyte carcinoma was more common in females younger than 55 years (Figure 2).

Between 2008 and 2017, females and males had a similar overall trend in incidence, with an AAPC of $1.9 \%(95 \% \mathrm{Cl} 1.7 \%$ to $2.1 \%$ ) and $1.8 \%(95 \% \mathrm{Cl} 1.7 \%$ to $2.0 \%)$, respectively. Stratified by age, the rates of increase in annual incidence among females aged 45-64 years significantly outpaced that in males of the same age group $(p \leq 0.01)$, though AAPCs were similar between sexes for ages $18-44$ years and 65 years and older (Figure 3 ). The relative increase in annual incidence rates was highest in adults younger than 35 years (AAPC $3.0 \%, 95 \% \mathrm{Cl} 1.4 \%$ to $4.6 \%$ in females; $2.9 \%, 95 \% \mathrm{Cl} 1.2 \%$ to $4.6 \%$ in males) (Figure 3 ).

Age-standardized incidence rates of keratinocyte carcinoma were higher with increasing income quintile (Figure 4). Males in all quintiles had higher rates of keratinocyte carcinoma than females. The rate of increase in incidence from 2008 to 2017 did not differ significantly between sexes in any income quintile, with AAPCs ranging from $0.62 \%$ to $1.02 \%$.

Annual mortality rates of keratinocyte carcinoma increased 4.8-fold over the study period, from a crude incidence of 6.39 deaths per 1000000 adults in 1998 to 30.53 deaths per 1000000 in 2017 (Table 1). The rate of increase in mortality did not differ significantly between males and females (AAPC $8.9 \%$, $95 \% \mathrm{Cl} 6.4 \%$ to $11.4 \%$ v. $8.0 \%, 95 \% \mathrm{Cl} 5.3 \%$ to $10.8 \%, p=0.6$ ) from 1998 to 2017. Annual mortality rates were 1.3 to 2.7 (median 1.8) times higher in males than females (Figure 5).

The median age of death for the entire observation period was 81 (interquartile range [IQR] 73-88) years for males and 86 (IQR 78-92) years for females. Most deaths from keratinocyte carcinoma occurred in adults aged 65 years or older, with $92.6 \%$ and $91.6 \%$ of deaths of males and females, respectively, occurring in this age group. When stratified by sex and age, the annual mortality rates from keratinocyte carcinoma increased at a faster rate in adults aged 65 years and older (AAPC 7.7\%, 95\% Cl 4.7\% to $10.8 \%$ in females; $8.9 \%, 95 \% \mathrm{Cl} 6.1 \%$ to $11.7 \%$ in males) than younger adults (AAPC $4.7 \%, 95 \% \mathrm{Cl} 2.9 \%$ to $6.6 \%$ for both sexes combined, $p=0.01$ ) from 1998 to 2017 (Appendix 1, 


\begin{tabular}{|c|c|c|c|c|c|c|}
\hline $\begin{array}{l}\text { Year of } \\
\text { diagnosis }\end{array}$ & $\begin{array}{l}\text { No. of adults } \\
\text { with first KC }\end{array}$ & $\begin{array}{l}\text { No. of } \\
\text { deaths } \\
\text { from KC }\end{array}$ & $\begin{array}{l}\text { Crude incidence } \\
\text { rate per } 100000 \\
(95 \% \mathrm{Cl})\end{array}$ & $\begin{array}{c}\text { Standardized } \\
\text { incidence rate per } \\
100000(95 \% \mathrm{Cl})^{\star}\end{array}$ & $\begin{array}{l}\text { Crude mortality } \\
\text { rate per } 1000000 \\
(95 \% \mathrm{Cl})\end{array}$ & $\begin{array}{c}\text { Standardized } \\
\text { mortality rate per } \\
1000000(95 \% \mathrm{Cl})^{\star}\end{array}$ \\
\hline 1998 & 29320 & 57 & $\begin{array}{c}328.6 \\
(324.9-332.4)\end{array}$ & $\begin{array}{c}306.2 \\
(302.7-309.7)\end{array}$ & $\begin{array}{c}6.39 \\
(4.84-8.28)\end{array}$ & $\begin{array}{c}5.79 \\
(4.38-7.50)\end{array}$ \\
\hline 1999 & 28811 & 74 & $\begin{array}{c}317.3 \\
(313.7-321.0)\end{array}$ & $\begin{array}{c}293.4 \\
(290.0-296.9)\end{array}$ & $\begin{array}{c}8.15 \\
(6.40-10.23)\end{array}$ & $\begin{array}{c}7.39 \\
(5.80-9.30)\end{array}$ \\
\hline 2000 & 28261 & 75 & $\begin{array}{c}305.2 \\
(301.7-308.8)\end{array}$ & $\begin{array}{c}279.7 \\
(276.4-283.0)\end{array}$ & $\begin{array}{c}8.10 \\
(6.37-10.15)\end{array}$ & $\begin{array}{c}7.13 \\
(5.60-8.95)\end{array}$ \\
\hline 2001 & 28783 & 73 & $\begin{array}{c}304.2 \\
(300.7-307.7)\end{array}$ & $\begin{array}{c}276.5 \\
(273.3-279.8)\end{array}$ & $\begin{array}{c}7.71 \\
(6.05-9.70)\end{array}$ & $\begin{array}{c}6.63 \\
(5.19-8.35)\end{array}$ \\
\hline 2002 & 27453 & 85 & $\begin{array}{c}285.5 \\
(282.2-288.9)\end{array}$ & $\begin{array}{c}257.3 \\
(254.2-260.3)\end{array}$ & $\begin{array}{c}8.84 \\
(7.06-10.93)\end{array}$ & $\begin{array}{c}7.39 \\
(5.89-9.15)\end{array}$ \\
\hline 2003 & 26765 & 149 & $\begin{array}{c}274.2 \\
(271.0-277.5)\end{array}$ & $\begin{array}{c}244.7 \\
(241.8-247.7)\end{array}$ & $\begin{array}{c}15.27 \\
(12.91-17.92)\end{array}$ & $\begin{array}{c}12.34 \\
(10.43-14.51)\end{array}$ \\
\hline 2004 & 27462 & 160 & $\begin{array}{c}277.4 \\
(274.2-280.7)\end{array}$ & $\begin{array}{c}245.2 \\
(242.3-248.2)\end{array}$ & $\begin{array}{c}16.16 \\
(13.76-18.87)\end{array}$ & $\begin{array}{c}12.85 \\
(10.92-15.03)\end{array}$ \\
\hline 2005 & 28669 & 145 & $\begin{array}{c}285.8 \\
(282.5-289.1)\end{array}$ & $\begin{array}{c}250.0 \\
(247.1-253.0)\end{array}$ & $\begin{array}{c}14.45 \\
(12.2-17.01)\end{array}$ & $\begin{array}{c}11.06 \\
(9.32-13.04)\end{array}$ \\
\hline 2006 & 29972 & 150 & $\begin{array}{c}296.6 \\
(293.3-300.0)\end{array}$ & $\begin{array}{c}255.8 \\
(252.9-258.8)\end{array}$ & $\begin{array}{c}14.85 \\
(12.57-17.42)\end{array}$ & $\begin{array}{c}10.99 \\
(9.28-12.93)\end{array}$ \\
\hline 2007 & 29646 & 194 & $\begin{array}{c}291.2 \\
(287.9-294.5)\end{array}$ & $\begin{array}{c}247.6 \\
(244.7-250.5)\end{array}$ & $\begin{array}{c}19.05 \\
(16.47-21.93)\end{array}$ & $\begin{array}{c}13.93 \\
(12.01-16.06)\end{array}$ \\
\hline 2008 & 31109 & 204 & $\begin{array}{c}301.5 \\
(298.2-304.9)\end{array}$ & $\begin{array}{c}254.1 \\
(251.2-257.0)\end{array}$ & $\begin{array}{c}19.77 \\
(17.15-22.68)\end{array}$ & $\begin{array}{c}14.24 \\
(12.32-16.39)\end{array}$ \\
\hline 2009 & 31890 & 250 & $\begin{array}{c}304.3 \\
(300.9-307.6)\end{array}$ & $\begin{array}{c}253.9 \\
(251.1-256.8)\end{array}$ & $\begin{array}{c}23.85 \\
(20.99-27)\end{array}$ & $\begin{array}{c}16.66 \\
(14.62-18.9)\end{array}$ \\
\hline 2010 & 32980 & 279 & $\begin{array}{c}310.4 \\
(307.1-313.8)\end{array}$ & $\begin{array}{c}255.6 \\
(252.7-258.4)\end{array}$ & $\begin{array}{c}26.26 \\
(23.27-29.53)\end{array}$ & $\begin{array}{c}18.29 \\
(16.15-20.64)\end{array}$ \\
\hline 2011 & 35209 & 250 & $\begin{array}{c}326.4 \\
(323.0-329.8)\end{array}$ & $\begin{array}{c}266.5 \\
(263.6-269.3)\end{array}$ & $\begin{array}{c}23.17 \\
(20.39-26.23)\end{array}$ & $\begin{array}{c}15.61 \\
(13.68-17.73)\end{array}$ \\
\hline 2012 & 35217 & 286 & $\begin{array}{c}322.0 \\
(318.6-325.4)\end{array}$ & $\begin{array}{c}259.4 \\
(256.6-262.2)\end{array}$ & $\begin{array}{c}26.15 \\
(23.21-29.36)\end{array}$ & $\begin{array}{c}17.34 \\
(15.32-19.54)\end{array}$ \\
\hline 2013 & 37051 & 306 & $\begin{array}{c}334.3 \\
(330.9-337.7)\end{array}$ & $\begin{array}{c}266.2 \\
(263.4-269)\end{array}$ & $\begin{array}{c}27.61 \\
(24.60-30.88)\end{array}$ & $\begin{array}{c}17.33 \\
(15.39-19.44)\end{array}$ \\
\hline 2014 & 37572 & 312 & $\begin{array}{c}335.9 \\
(332.6-339.4)\end{array}$ & $\begin{array}{c}263.5 \\
(260.7-266.2)\end{array}$ & $\begin{array}{c}27.90 \\
(24.89-31.17)\end{array}$ & $\begin{array}{c}17.22 \\
(15.30-19.32)\end{array}$ \\
\hline 2015 & 38593 & 316 & $\begin{array}{c}341.8 \\
(338.4-345.2)\end{array}$ & $\begin{array}{c}264.7 \\
(262-267.4)\end{array}$ & $\begin{array}{c}27.98 \\
(24.98-31.25)\end{array}$ & $\begin{array}{c}17.02 \\
(15.13-19.09)\end{array}$ \\
\hline 2016 & 40475 & 358 & $\begin{array}{c}353.9 \\
(350.5-357.4)\end{array}$ & $\begin{array}{c}271.2 \\
(268.5-273.9)\end{array}$ & $\begin{array}{c}31.31 \\
(28.15-34.72)\end{array}$ & $\begin{array}{c}18.65 \\
(16.69-20.77)\end{array}$ \\
\hline 2017 & 41242 & 353 & $\begin{array}{c}356.7 \\
(353.2-360.1)\end{array}$ & $\begin{array}{c}271.0 \\
(268.3-273.7)\end{array}$ & $\begin{array}{c}30.53 \\
(27.43-33.89)\end{array}$ & $\begin{array}{c}17.22 \\
(15.40-19.19)\end{array}$ \\
\hline
\end{tabular}

Figure S1). We did not observe any consistent differences in mortality rates across income quintiles (Appendix 1, Figure S2).

After adjusting the incidence and mortality rates to reflect diagnoses of keratinocyte carcinoma in white adults, the trends were similar but with greater magnitudes of annual increases compared with the entire population (Appendix 1, Table S1). The AAPC for incidence of keratinocyte carcinoma in white adults was $2.8 \%$ (95\% Cl 2.6\% to $3.0 \%$ ) from 2008 to 2017 , and the AAPC for deaths from keratinocyte carcinoma was 9.4\% (95\% Cl 7.3\% to $11.7 \%$ ) from 1998 to 2017.

\section{Interpretation}

We identified a growing burden of incidence of and death related to keratinocyte carcinoma in Ontario. Our findings highlight the importance of stratifying by age when evaluating 


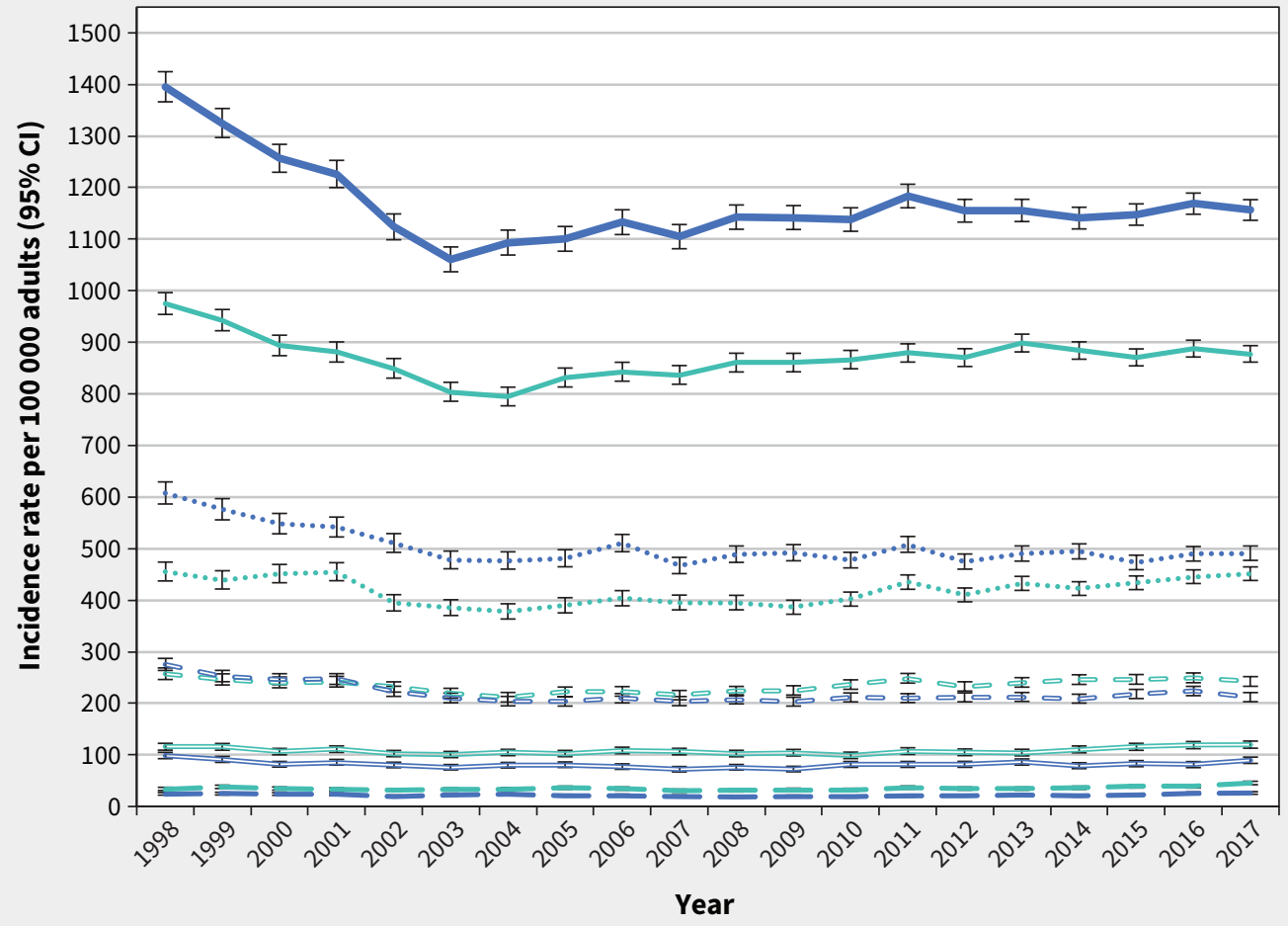

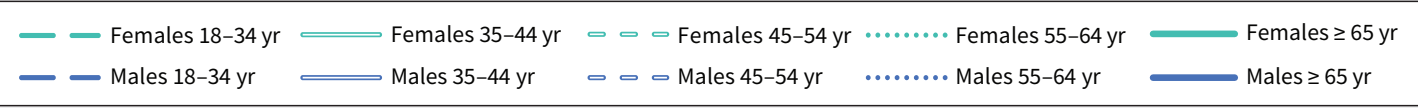

Figure 2: Annual crude incidence rates of first diagnosis of keratinocyte carcinoma by age and sex among Ontario adults (1998-2017). Note: $\mathrm{Cl}=$ confidence interval.

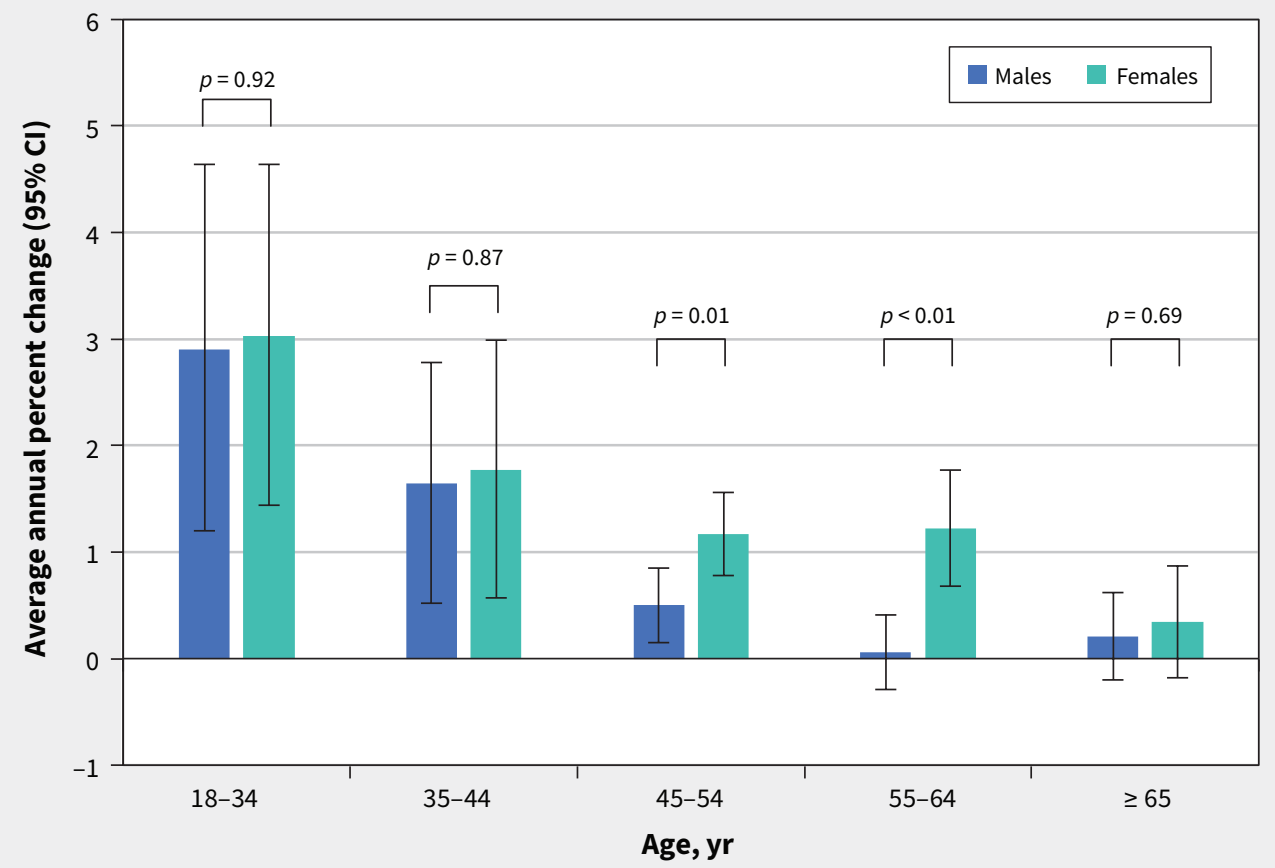

Figure 3: Average annual percent change in incidence rates of keratinocyte carcinoma by age and sex among Ontario adults from 2008 to 2017 . The $p$ value represents the pairwise comparison between males and females. Note: $\mathrm{Cl}=$ confidence interval. 


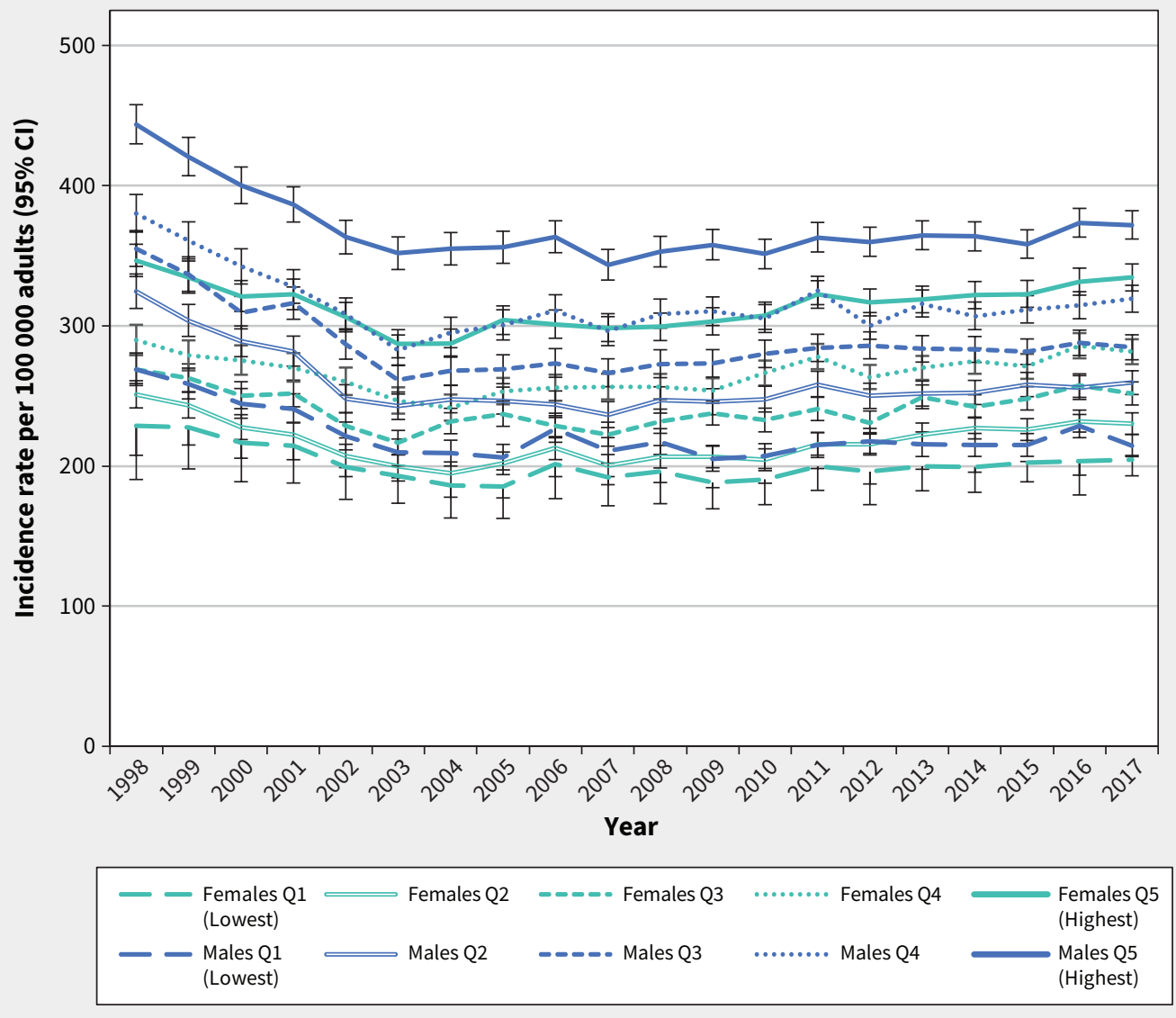

Figure 4: Annual age-standardized incidence rates of first diagnosis of keratinocyte carcinoma by income quintile (Q1-Q5) and sex among Ontario adults (1998-2017). Incidence rates were age-standardized using the 1991 Canadian population. Note: $\mathrm{Cl}=$ confidence interval.

differences by sex in a population. Younger females had a higher incidence of keratinocyte carcinoma and the most rapidly increasing rates compared with similarly aged males, but the incidence was higher in males than females in older age groups and higher income quintiles. On average, annual mortality rates from keratinocyte carcinoma were twice as high in males than in females, and rose 4 times faster than the incidence in both sexes. Adjustment for white race produced similar but amplified trends.

We found that the incidence of keratinocyte carcinoma was much higher in Ontario than previous reports from other Canadian provinces. ${ }^{3,4,33-36}$ One explanation is our validated method to ascertain keratinocyte carcinoma using health insurance claims. Previous studies of cancer registries likely underestimated the incidence of keratinocyte carcinoma; these common cancers are known to be under-reported because patients often receive treatment in community settings rather than hospital-based cancer centres. ${ }^{37-39}$

The decline in incidence of keratinocyte carcinoma that we observed from 1998 to 2003 could potentially be attributed to skin cancer prevention campaigns in the 1980 s and 1990 s. $^{40}$ Between 1996 and 2006, the use of artificial tanning booths increased and sun protective behaviours reduced among people in Ontario, ${ }^{41}$ which could have contributed to the rise in incidence of keratinocyte carcinoma after 2003 that was also seen in other Canadian provinces. . $^{3,433-36}$

Although older age is a well-established risk factor for keratinocyte carcinoma because of greater cumulative sun exposure,,${ }^{11}$ differences in the development of keratinocyte carcinoma by sex may arise from biological susceptibility and behavioural factors. ${ }^{10-14}$ Evidence suggests that males are more likely to have outdoor occupations and are less likely to engage in sun protective behaviours, and females are more likely to seek a tan through artificial tanning booths and sun exposure. ${ }^{41-44}$ Exposure to tanning is highest in young females and declines with age, which could explain the increasing incidence of keratinocyte carcinoma in younger females. ${ }^{43-46}$ Females are also more likely to conduct skin self-examinations, which could lead to diagnosis at a younger age than males. ${ }^{47-51}$

The association between income and keratinocyte carcinoma in our population is consistent with studies conducted in Denmark, Finland and England. ${ }^{18-21}$ Increased socioeconomic status likely enables vacations to sunny destinations, and is associated with higher levels of education and ability to take time off work to seek medical care and diagnose keratinocyte carcinoma. ${ }^{50-52}$ Further, visible minorities in Canada have lower average incomes 


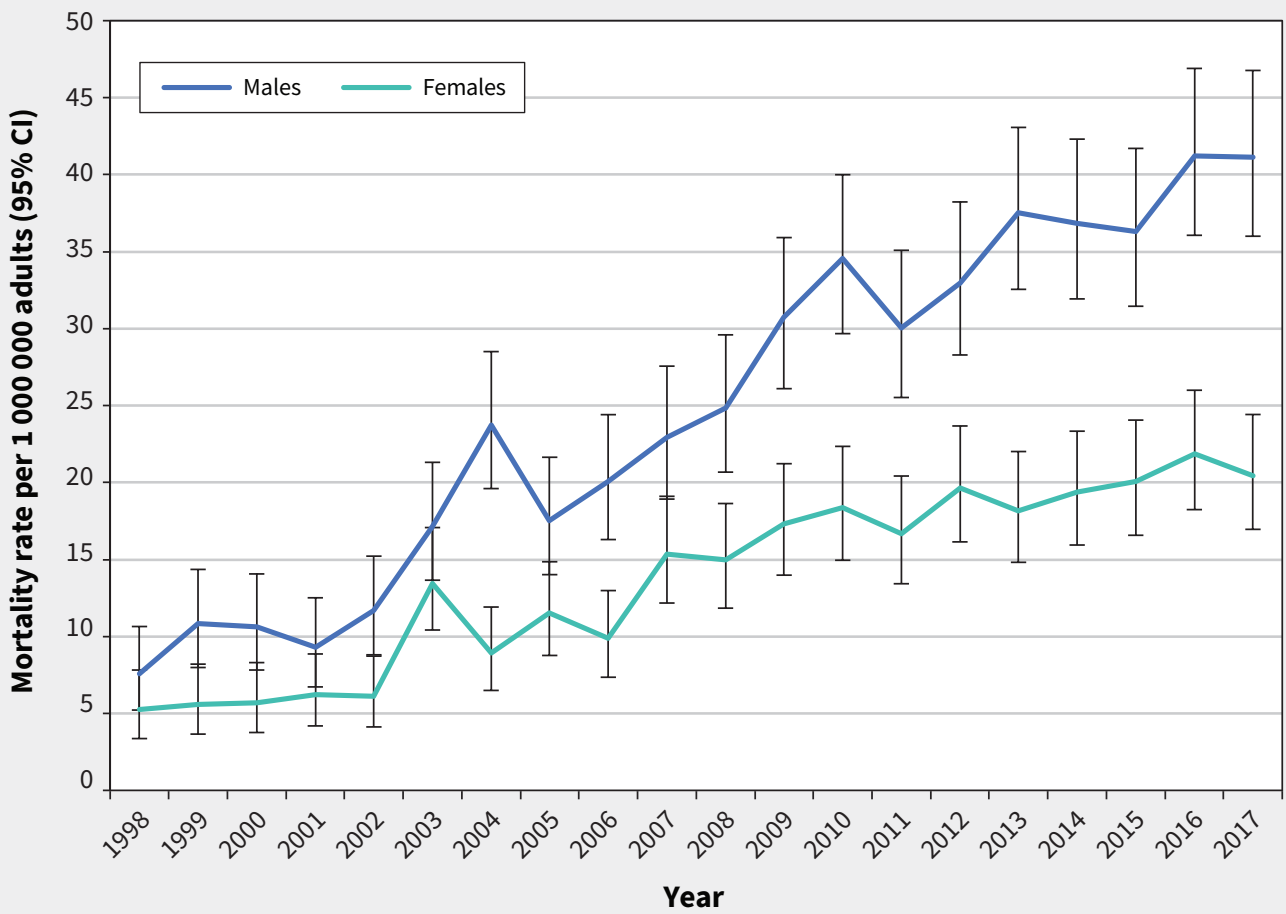

Figure 5: Annual crude mortality rates of keratinocyte carcinoma by sex among Ontario adults (1998-2017). Note: $\mathrm{Cl}=$ confidence interval.

and are considered to have lower risk of keratinocyte carcinoma if they have darker skin pigmentation. ${ }^{53,54}$

Deaths from keratinocyte carcinoma in our study can be attributed to squamous cell carcinoma, as metastasis is extremely rare for basal cell carcinoma. ${ }^{55}$ The disproportionate rise in mortality rates relative to incidence could arise if squamous cell carcinomas had worsening outcomes or accounted for an increasing proportion of keratinocyte carcinoma over the study period. ${ }^{56}$ Our findings contrast with declining mortality rates observed in the US, Finland and Germany. ${ }^{12,20,57-59}$ Consistent with our results, older studies found higher mortality rates among males than females. ${ }^{12,20,57-59}$ Differences in mortality rates by sex have been observed in other skin cancers and may arise from biological and lifestyle factors. ${ }^{60-62}$

\section{Limitations}

The claims-based algorithm cannot identify keratinocyte carcinoma treated without biopsy or surgery. ${ }^{27}$ We expect this to be rare, as billing for the treatment of keratinocyte carcinoma in Ontario requires a documented biopsy. Further, the algorithm was unable to ascertain tumour stage or distinguish basal versus squamous cell carcinoma, which may have different incidence and mortality trends. We deliberately chose to evaluate the first incidence of keratinocyte carcinoma, which means we greatly underestimated the total burden of keratinocyte carcinoma because multiple primary tumours commonly arise in a given individual. Our lookback period of at least 6 years would have captured most instances of prior keratinocyte carcinoma to define incident cases, because a second keratinocyte carcinoma typically occurs within 5 years of the first tumour; ${ }^{63,64}$ however, it is possible that some individuals with keratinocyte carcinoma before 1992 were misclassified as having their first keratinocyte carcinoma. It is also possible that a change in recording behaviour on death certificates over time led to the observed increases in deaths from keratinocyte carcinoma, but it is unlikely that there would be a constantly increasing tendency to record keratinocyte carcinoma as a cause of death over the 20-year period. The use of postal codes to estimate an individual's socioeconomic status is susceptible to ecological bias. For our secondary analysis, we assumed that $97 \%$ of patients with keratinocyte carcinoma were white based on an Ontario cohort of transplant recipients, which may not represent the general population. However, the estimate is similar to proportions found in Florida, California and national US databases (91.4\%-99.6\%). ${ }^{65-68}$

\section{Conclusion}

Our study highlights differences by sex in population-based estimates of keratinocyte carcinoma in Ontario, Canada. The increasing incidence rates (particularly in younger females) and disproportionately rising mortality rates of keratinocyte carcinoma are concerning. Further research is necessary to evaluate the reasons for the epidemiological trends. Renewed public health efforts are warranted to promote preventive measures, patient education and early diagnosis. 


\section{References}

1. Karimkhani C, Boyers LN, Dellavalle RP, et al. It's time for "keratinocyte carcinoma" to replace the term "nonmelanoma skin cancer". J Am Acad Dermatol 2015;72:186-7.

2. Apalla Z, Nashan D, Weller RB, et al. Skin cancer: epidemiology, disease burden, pathophysiology, diagnosis, and therapeutic approaches. Dermatol Ther (Heidelb) 2017;7(Suppl 1):5-19.

3. McLean DI, Phillips N, Zhou Y, et al. 40-year trends in skin cancer in British Columbia, Canada, 1973 to 2003. J Cutan Med Surg 2012;16:83-91.

4. Pilgrim W, Hayes R, Hanson DW, et al. Skin cancer (basal cell carcinoma, squamous cell carcinoma, and malignant melanoma): new cases, treatment practice, and health care costs in New Brunswick, Canada, 2002-2010. J Cutan Med Surg 2014;18:320-31.

5. Lim HW, Collins SAB, Resneck JS Jr, et al. The burden of skin disease in the United States. J Am Acad Dermatol 2017;76:958-972.e2.

6. Guy GP, Ekwueme DU. Years of potential life lost and indirect costs of melanoma and non-melanoma skin cancer: a systematic review of the literature. PharmacoEconomics 2011;29:863-74.

7. Rogers HW, Weinstock MA, Harris AR, et al. Incidence estimate of nonmelanoma skin cancer in the United States, 2006. Arch Dermatol 2010;146:283-7.

8. Housman TS, Feldman SR, Williford PM, et al. Skin cancer is among the most costly of all cancers to treat for the medicare population. J Am Acad Dermatol 2003;48:425-9.

9. Brenner DR, Ruan Y, Shaw E, et al. Age-standardized cancer-incidence trends in Canada, 1971-2015. CMAJ 2019;191:E1262.

10. Oberyszyn TM. Non-melanoma skin cancer: importance of gender, immunosuppressive status and vitamin D. Cancer Lett 2008;261:127-36.

11. Armstrong BK, Kricker A. The epidemiology of UV induced skin cancer. J Photochem Photobiol B 2001;63:8-18.

12. Leiter $\mathrm{U}$, Keim $\mathrm{U}$, Eigentler $\mathrm{T}$, et al. Incidence, mortality, and trends of nonmelanoma skin cancer in Germany. J Invest Dermatol 2017;137:1860-7.

13. Apalla Z, Lallas A, Sotiriou E, et al. Epidemiological trends in skin cancer. Dermatol Pract Concept 2017;7:1-6.

14. Thomas-Ahner JM, Wulff BC, Tober KL, et al. Gender differences in uvb-induced skin carcinogenesis, inflammation, and DNA damage. Cancer Res 2007;67:3468-74.

15. Dacosta Byfield S, Chen D, Yim YM, et al. Age distribution of patients with advanced non-melanoma skin cancer in the United States. Arch Dermatol Res 2013;305:845-50.

16. Karagas MR, Greenberg ER, Spencer SK, et al. Increase in incidence rates of basal cell and squamous cell skin cancer in New Hampshire, USA. New Hampshire skin cancer study group. Int J Cancer 1999;81:555-9.

17. Eisemann N, Waldmann A, Geller AC, et al. Non-melanoma skin cancer incidence and impact of skin cancer screening on incidence. J Invest Dermatol 2014;134:43-50.

18. Steding-Jessen M, Birch-Johansen F, Jensen A, et al. Socioeconomic status and non-melanoma skin cancer: a nationwide cohort study of incidence and survival in Denmark. Cancer Epidemiol 2010;34:689-95.

19. Lear JT, Tan BB, Smith AG, et al. A comparison of risk factors for malignant melanoma, squamous cell carcinoma and basal cell carcinoma in the UK. Int $J$ Clin Pract 1998;52:145-9.

20. Hannuksela-Svahn A, Pukkala E, Karvonen J. Basal cell skin carcinoma and other nonmelanoma skin cancers in Finland from 1956 through 1995. Arch Dermatol 1999;135:781-6.

21. Wheeler BW, Kothencz G, Pollard AS. Geography of non-melanoma skin cancer and ecological associations with environmental risk factors in England. $\mathrm{Br} \mathrm{J}$ Cancer 2013;109:235-41.

22. FDA approves cemiplimab-rwlc for cutaneous squamous cell carcinoma. Silver Spring (MD): US Food and Drug Administration, Center for Drug Evaluation and Research; 2019. Available: https://www.fda.gov/drugs/drug-approvals -and-databases/fda-approves-cemiplimab-rwlc-metastatic-or-locally-advanced -cutaneous-squamous-cell-carcinoma (accessed 2021 June 4).

23. FDA approves pembrolizumab for cutaneous squamous cell carcinoma. Silver Spring (MD): US Food and Drug Administration, Center for Drug Evaluation and Research; 2020. Available: https://www.fda.gov/drugs/drug-approvals -and-databases/fda-approves-pembrolizumab-cutaneous-squamous-cell -carcinoma (accessed 2021 June 4).

24. FDA approves cemiplimab-rwlc for locally advanced and metastatic basal cell carcinoma. Silver Spring (MD): US Food and Drug Administration, Center for Drug Evaluation and Research; 2021. Available: https://www.fda.gov/drugs/ resources-information-approved-drugs/fda-approves-cemiplimab-rwlc-locally -advanced-and-metastatic-basal-cell-carcinoma (accessed 2021 June 4).
25. Libtayo - notice of compliance with conditions - qualifying notice. Ottawa: Health Canada; 2019. Available: https://www.canada.ca/en/health-canada/ services/drugs-health-products/drug-products/notice-compliance/conditions/ libtayo-notice-compliance-conditions-218718.html (accessed 2021 June 21).

26. Benchimol El, Smeeth L, Guttmann A, et al. The REporting of studies Conducted using Observational Routinely-collected health Data (RECORD) statement. PLoS Med 2015;12:e1001885.

27. Chan AW, Fung K, Tran JM, et al. Application of recursive partitioning to derive and validate a claims-based algorithm for identifying keratinocyte carcinoma (nonmelanoma skin cancer). JAMA Dermatol 2016;152:1122-7.

28. Brenner DR, Tammemägi M, Bull S, et al. Using cancer registry data: agreement in cause-of-death data between the Ontario cancer registry and a longitudinal study of breast cancer patients. Chronic Dis Can 2009;30:16-9.

29. Kim HJ, Fay MP, Feuer EJ, et al. Permutation tests for joinpoint regression with applications to cancer rates. Stat Med 2000;19:335-51.

30. Kim HJ, Fay MP, Yu B, et al. Comparability of segmented line regression models. Biometrics 2004;60:1005-14.

31. Park CK, Fung K, Austin PC, et al. Incidence and risk factors of keratinocyte carcinoma after first solid organ transplant in Ontario, Canada. JAMA Dermatol 2019;155:1041-8.

32. Table 17-10-0005-01 population estimates on July 1st, by age and sex. Ottawa: Statistics Canada; 2020.

33. Hayes RC, Leonfellner S, Pilgrim W, et al. Incidence of nonmelanoma skin cancer in New Brunswick, Canada, 1992 to 2001. J Cutan Med Surg 2007;11:45-52.

34. Jung GW, Metelitsa A, Dover D, et al. Trends in incidence of nonmelanoma skin cancers in Alberta, Canada, 1988-2007. Br J Dermatol 2010;163:146-54.

35. Demers AA, Nugent Z, Mihalcioiu C, et al. Trends of nonmelanoma skin cancer from 1960 through 2000 in a Canadian population. J Am Acad Dermatol 2005;53:320-8.

36. Gallagher RP, Ma B, McLean DI, et al. Trends in basal cell carcinoma, squamous cell carcinoma, and melanoma of the skin from 1973 through 1987. J Am Acad Dermatol 1990;23:413-21.

37. Lamberg AL, Cronin-Fenton D, Olesen AB. Registration in the Danish regional nonmelanoma skin cancer dermatology database: completeness of registration and accuracy of key variables. Clin Epidemiol 2010;2:123-36.

38. Tran JM, Schwartz R, Fung K, et al. Comprehensive capture of cutaneous melanoma by the Ontario cancer registry: validation study using community pathology reports. Cancer Causes Control 2016;27:137-42.

39. Tokez S, Hollestein L, Louwman M, et al. Incidence of multiple vs first cutaneous squamous cell carcinoma on a nationwide scale and estimation of future incidences of cutaneous squamous cell carcinoma. JAMA Dermatol 2020;156:1300-6.

40. Marrett LD, Broadhurst D, Charron S, et al. The Ontario sun safety working group. Chronic Dis Can 2003;24:27-31.

41. Ontario Sun Safety Working Group. Insight on cancer: sun exposure and protective behaviours in Ontario: an Ontario report based on the 2006 second national sun survey. Toronto: Canadian Cancer Society and Cancer Care Ontario; 2010.

42. Hall HI, May DS, Lew RA, et al. Sun protection behaviors of the US white population. Prev Med 1997;26:401-7.

43. Wehner MR, Shive ML, Chren MM, et al. Indoor tanning and non-melanoma skin cancer: systematic review and meta-analysis. BMJ 2012;345:e5909.

44. Qutob SS, O'Brien M, Feder K, et al. Tanning equipment use: 2014 Canadian community health survey. Ottawa: Statistics Canada; 2017.

45. Dennis LK, Kancherla V, Snetselaar LG. Adolescent attitudes towards tanning: Does age matter? Ped Health 2009;3:565-78.

46. Dennis LK, Lowe JB, Snetselaar LG. Tanning behavior among young frequent tanners is related to attitudes and not lack of knowledge about the dangers. Health Educ J 2009;68:232-43.

47. Federman DG, Kravetz JD, Ma F, et al. Patient gender affects skin cancer screening practices and attitudes among veterans. South Med J 2008;101: 513-8.

48. Chen J, Shih J, Tran A, et al. Gender-based differences and barriers in skin protection behaviors in melanoma survivors. J Skin Cancer 2016;2016:3874572.

49. Sun safe behavior survey. Ottawa: Canadian Dermatology Association; 2019.

50. Agarwal SB, Godse K, Patil S, et al. Knowledge and attitude of general population toward effects of sun exposure and use of sunscreens. Indian J Dermatol 2018;63:285-91.

51. Yan S, Xu F, Yang C, et al. Demographic differences in sun protection beliefs and behavior: A community-based study in Shanghai, China. Int J Environ Res Public Health 2015;12:3232-45.

52. Pinault L, Fioletov V. Sun exposure, sun protection and sunburn among Canadian adults. Ottawa: Statistics Canada; 2017. 
53. Block S, Galabuzi G-E, Tranjan R. Canada's colour-coded income inequality. Ottawa: Canadian Centre for Policy Alternatives; 2019.

54. Ferron TR. Ethno-racial groups and income attainment in Canada: investigating the mosaic [thesis]. Windsor (ON): University of Windsor; 2005

55. Nguyen TH. Mechanisms of metastasis. Clin Dermatol 2004;22:209-16.

56. Ciazynska M, Kaminska-Winciorek G, Lange D, et al. The incidence and clinical analysis of non-melanoma skin cancer. Sci Rep 2021;11:4337.

57. Stang A, Jöckel KH. Declining mortality rates for nonmelanoma skin cancers in West Germany, 1968-99. Br J Dermatol 2004;150:517-22.

58. Lewis KG, Weinstock MA. Trends in nonmelanoma skin cancer mortality rates in the United States, 1969 through 2000. J Invest Dermatol 2007;127:2323-7.

59. Lewis KG, Weinstock MA. Nonmelanoma skin cancer mortality (1988-2000): the Rhode Island follow-back study. Arch Dermatol 2004;140:837-42.

60. Kim H-I, Lim H, Moon A. Sex differences in cancer: epidemiology, genetics and therapy. Biomol Ther (Seoul) 2018;26:335-42.

61. Tam M, Luu M, Barker CA, et al. Improved survival in women versus men with merkel cell carcinoma. J Am Acad Dermatol 2021;84:321-9.

62. Schwartz MR, Luo L, Berwick M. Sex differences in melanoma. Curr Epidemiol Rep 2019;6:112-8.
63. Rodriguez M, Beal BT, Manmohan M, et al. Risk factors and timing of subsequent cutaneous squamous cell carcinoma in patients with cutaneous squamous cell carcinoma: a retrospective cohort study. J Am Acad Dermatol 2021; 84:719-24.

64. Marcil I, Stern RS. Risk of developing a subsequent nonmelanoma skin cancer in patients with a history of nonmelanoma skin cancer: a critical review of the literature and meta-analysis. Arch Dermatol 2000;136:1524-30.

65. Perper M, Shah V, Tsatalis J, et al. Keratinocyte carcinoma data for Hispanic patients undergoing mohs micrographic surgery in Miami, Florida from 2011 to 2014. J Am Acad Dermatol 2017;77:580-2.

66. Wu S, Cho E, Li WQ, et al. History of keratinocyte carcinoma and risk of melanoma: a prospective cohort study. J Natl Cancer Inst 2017;109:djw268.

67. Loh TY, Ortiz A, Goldenberg A, et al. Prevalence and clinical characteristics of nonmelanoma skin cancers among Hispanic and Asian patients compared with White patients in the United States: a 5-year, single-institution retrospective review. Dermatol Surg 2016;42:639-45.

68. Lukowiak TM, Aizman L, Perz A, et al. Association of age, sex, race, and geographic region with variation of the ratio of basal cell to cutaneous squamous cell carcinomas in the United States. JAMA Dermatol 2020;156:1192-8.
Competing interests: An-Wen Chan reports funding from Pellepharm to his institution to support participation as a clinical trial site, outside the submitted work. No other competing interests were declared.

This article has been peer reviewed.

Affiliations: Faculty of Medicine (Tang), University of Toronto; ICES (Fung, Chan); Division of Dermatology, Department of Medicine (Tang, Chan), Women's College Research Institute, Women's College Hospital, Toronto, Ont.

Contributors: An-Wen Chan and Kinwah Fung contributed to the conception and design of the work. All of the authors contributed to the acquisition, analysis and interpretation of data. Evan Tang and An-Wen Chan drafted the manuscript. All of the authors revised the manuscript critically for important intellectual content, gave final approval of the version to be published and agreed to be accountable for all aspects of the work.

Content licence: This is an Open Access article distributed in accordance with the terms of the Creative Commons Attribution (CC BY-NC-ND
4.0) licence, which permits use, distribution and reproduction in any medium, provided that the original publication is properly cited, the use is noncommercial (i.e., research or educational use), and no modifications or adaptations are made. See: https://creativecommons. org/licenses/by-nc-nd/4.0/

Funding: This work was funded by operating grants from the Canadian Dermatology Foundation, Biggar-Hedges Foundation and Skin Cancer Canada. The funding sources had no role in the design and conduct of the study; collection, management, analysis, and interpretation of the data; preparation, review, or approval of the manuscript; and decision to submit the manuscript for publication.

Data sharing: The data set from this study is held securely in coded form at ICES. Although legal data sharing agreements between ICES and data providers (e.g., health care organizations and government) prohibit ICES from making the data set publicly available, access may be granted to those who meet prespecified criteria for confidential access, available at https://www.ices.on.ca/DAS. The full data set creation plan and underlying analytic code are available from the authors upon request understanding that the computer programs may rely upon coding templates or macros that are unique to ICES and are therefore either inaccessible or may require modification.

Disclaimer: The study was supported by ICES (formerly the Institute for Clinical Evaluative Sciences), which is funded by an annual grant from the Ontario Ministry of Health and LongTerm Care. Parts of this material are based on data and information compiled and provided by: Ontario Ministry of Health and Long-Term Care, Canadian Institute of Health Information, Cancer Care Ontario, and Ontario Registrar General (information on deaths, the original source of which is ServiceOntario). The analyses, conclusions, opinions and statements expressed herein are solely those of the authors and do not reflect those of the funding or data sources; no endorsement is intended or should be inferred.

Accepted: July 21, 2021

Correspondence to: An-Wen Chan, anwen. chan@utoronto.ca 